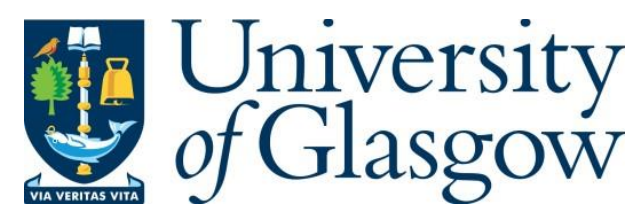

Manica, S. and Forgie, A. (2017) Forensic dentistry now and in the future. Dental Update, 44(6), pp. 522-530.

There may be differences between this version and the published version. You are advised to consult the publisher's version if you wish to cite from it.

http://eprints.gla.ac.uk/145523/

Deposited on: 31 August 2017

Enlighten - Research publications by members of the University of Glasgow http://eprints.gla.ac.uk 
a) Forensic dentistry

b) Forensic dentistry now and in the future

c) Scheila Manica, DDS, M. Sc., Ph.D. ${ }^{1}$

Andrew Forgie, BDS, PhD, FDS (Rest Dent) RCS(Ed), FDS RCPS(Glasg). ${ }^{2}$

d) ${ }^{1}$ Lecturer, Centre for Forensic and Legal Medicine, University of Dundee

${ }^{2}$ Senior Clinical University Teacher, Glasgow Dental Hospital and School, University of Glasgow 


\title{
Forensic dentistry now and in the future
}

\begin{abstract}
:
Forensic dentistry (odontology) deals with the proper examination, handling and presentation of dental evidence for the legal system. In the United Kingdom this work mainly involves criminal cases but in many other countries its remit also extends to civil litigation. There are four main aspects to forensic dentistry: single body identification, Disaster Victim Identification (DVI), age estimation and bite mark identification and analysis.

This article provides a brief introduction to the topics and discusses potential future developments that aim to reduce the subjectivity in the analysis process and simplify presentation of evidence to non-dental parties.
\end{abstract}

Clinical relevance: This article highlights ways that dental practitioners can assist legal investigations and in particular forensic dentists

Objectives: The reader should understand the scope of forensic dentistry and how research and future developments may help overcome current limitations in the field. 
Forensic dentistry is the application of dental knowledge in the service of criminal and civil laws. ${ }^{1}$ Following the publication of a short article in 1897 describing identification of victims of a fire in Paris by Dr. Oscar Amoedo who is considered to be 'the father of the forensic odontology $^{1,2}$, this branch of dentistry started to develop. The importance of age estimation was highlighted in the industrial revolution with the Factories Acts of $1819^{3}$ and $1884^{4}$ which determined the minimum age to work was 9 years and 8 years respectively with age verified by a surgeon. The individuality of bite marks has been known for many centuries. William the Conqueror had the habit of securing his mail with sealing wax imprinted with his bite to allow verification of authenticity of his documents: his anterior teeth were malaligned. In the United Kingdom the 1948 Gorringe case is often considered to be the start of modern day bite mark analysis ${ }^{5}$

\section{Single body identification}

Identification of deceased individuals makes up the majority of work for forensic dentists especially when identity is assumed eg from personal belongings or circumstantial evidence. Dental identification is usually requested when a body is not suitable for viewing by the family or if there is difficulty in retrieving DNA. From a more practical perspective dental identification is an excellent method as teeth are very stable over time being resilient to high temperature, trauma and variations in humidity and pressure. In addition, it is quick, accurate and relatively cheap. To establish identity, post-mortem (PM) dental remains are compared with ante-mortem (AM) dental records that can include dental charts, study casts, dental radiographs and photographs ${ }^{6}$. 
While a relatively straightforward process there are many obstacles to establishing a dental identification. The availability and accuracy of AM records is a major determinant in the success of identification ${ }^{7}$. Many studies have surveyed dentists' awareness of this and a recent paper found that students are more likely to keep accurate dental records than dentists in practice ${ }^{8}$. Poor record keeping is becoming less of a problem with the use of electronic patient records in developed countries although a full glossary of the symbols and colours used is very useful and not often available to the forensic dentist. The electronic dental record also has the advantages of easy handling, transfer, and opens up the possibility of rapid communication in forensic cases related to identification overseas 9 . However, in developing countries the quality of information recorded in notes varies significantly.

Radiographs can assist the process identification. Most well-resourced mortuaries should have access to intra-oral radiography and it is then a straightforward matter of duplicating the position and angulation of the ante-mortem radiograph to allow a comparison of the shape and size of restorations in the two radiographs ${ }^{10}$ (Figures 1a and b). In circumstances where there are no restorations it is still possible to identify through radiographic features such as pulp chamber anatomy, root shape and even bone trabeculae ${ }^{11}$. However, the reliability of this depends on the experience of the forensic dentist and the age of the AM radiograph ${ }^{12}$. Dental casts are also an excellent resource for identification as the body or casts of the victim can be and compared to the AM models (Figures $2 \mathrm{a}$ and $2 \mathrm{~b}$ ). This allows morphometric analysis of the teeth and also a comparison of palatal rugae that are considered to be as unique as fingerprints and stable throughout adult life ${ }^{13}$. If no specific dental records are available identification using photographs has been described ${ }^{14,15}$. The accuracy and reliability of this technique has not been established at a population level. With the reduction in dental experience of young people it is likely that this technique will become more 
important especially with the widespread use of "selfie" photographs which often focus on the smiling face.

If resources allow dental materials can also provide clues to assist identification. Scanning Electron Microscope/Energy Dispersive X-ray Spectroscopy (SEM EDXS) can be used to analyse restorative materials. Each material produces a unique spectrum allowing individual brands to be identified. SEM-EDX has been used to identify the composition of a glassionomer filling which was then traced back to a prison where the restoration was placed ${ }^{6}$. Electron probe analysis has also been used to identify the material found in a wound as that of the porcelain from a fractured dental bridge thereby linking the suspect and the victim ${ }^{16}$.

Even if the dental record cannot help with identification teeth can be used as a source of DNA which is then compared to a known AM sample or to a relative ${ }^{6}$. DNA analysis has been increasingly used in human identification procedures since the development of genetics in the 80 ' $\mathrm{s}^{17}$. The hard tooth tissues protect the pulpal DNA from external damage ${ }^{17}$. With severe body decomposition or skeletisation teeth may be the only feasible source of DNA with the dental hard tissues also able to be used for DNA extraction. Microscopic examination of teeth can confirm sex by the presence or absence of Y-chromatin and DNA analysis ${ }^{6}$.

\section{Clinical Relevance}

- Maintaining good notes is essential and would ideally include a full mouth charting.

- If sharing an electronic record please also send a legend of the symbols and colours used in the pictorial dental chart 
- If asked for dental records please include all radiographs, casts, photographs and any other information that may be relevant such as letters of referral.

If no ante mortem information of any form is available the forensic dentist may be asked to help with profiling. This situation is regularly found in cases when a body is recovered from the sea. If there are unusual dental features a press release can be prepared asking dentists if they recognise the dental work. In some circumstances a forensic dentist can estimate the age of the victim or the geographical region where the dental treatment was provided. Dental treatment styles vary across the globe and whilst it is unlikely to be able to establish an identification it may be of help to the police if the forensic dentist can suggest that the victim has had treatment abroad.

\section{Mass disasters}

Dental identification is also applied in disasters with a large number of fatalities; disaster victim identification (DVI). DNA matching, friction ridge (fingerprint) matching and dental comparison are the three primary identification techniques ie no other evidence is required to prove identity. Even with the increased awareness of DNA, dentistry still accounts for the vast majority of identifications. In many mass disasters identification is more challenging because of the presence of body fragmentation, commingling and psychological stress ${ }^{6}$. The process of identification is identical to single body identification but the logistics are much more demanding especially if the mass disaster is an "open" disaster with no list of victims which would be available in a "closed" disaster such as an air crash where a passenger manifest is available. Computer systems have been developed that assist with the 
administrative and identification processes. Plassdata (www.plassdata.com) is a comprehensive DVI software package that has been adopted by Interpol as it replicates the paperwork of the Interpol DVI guide. It has various sections including DNA, friction ridge, personal belongings, medical and dental. All the information relating to each body and suspected victim is stored in the system. Ante mortem and post mortem findings can then be electronically searched saving much manual work. It is important to highlight that the final identification decision is always made manually.

With the growing awareness about the importance of forensic odontologists in DVI incidents, dental graduates are encouraged to train and be part of identification teams ${ }^{18}$ (Figure 3). Many countries have established a DVI cadre who are trained in the use of plassdata, are experienced in dental identification and able to be deployed at short notice often overseas if nationals are killed abroad.

\section{Age estimation}

Age estimation is important for many social reasons and forensic dentists are increasingly being asked to assist. Dental age estimation in children considers tooth development and is amongst the most reliable indicators for age estimation up to the age of 16 years. From 16-24 years third molar development can be assessed but there is significant variability and the accuracy is controversial ${ }^{19}$. In adults age estimation is less precise and open to significant variation between individuals. The traditional dental changes that have been used are: secondary dentine formation, cementum deposition, root translucency and tooth wear. 
In children tooth development is determined genetically with only a small environmental contribution. Eruption dates are more variable and their use for age estimation is now limited.

The mass migration of refugees into developed countries is a current issue. In many cases the refugees are, or claim to be, children that hope to become asylum seekers. For those minors without valid proof of age, methods of age estimation must be reliable and accurate, so that, the forgery claims can be avoided and genuine minors will not be rejected. Most of them come from poor developing countries where patterns of dental maturation may differ due to genetics and nutritional status ${ }^{20}$. It is very challenging to predict to what extent these factors influence the accuracy of age estimation but some researchers claim that diet has no effect on the timing of teeth formation ${ }^{21}$ especially as the tooth being examined is often the third molar which exhibits high variation in development. Without an understanding of the population differences and the effect of various factors on growth of maturity indicators, some reference data to estimate age should be interpreted with caution. The most accurate method of age estimation of children is to compare tooth formation; crown and root formation against reference samples often controlled for sex and ethnicity. This is usually done radiographically using ortho pantomograms (OPGs) and is a high profile area of controversy in the United Kindom with much debate between politicians and the profession. Most other countries in Europe advocate the use of radiographs for age estimation. However, this debate is out with the scope of this article. Estimated age can be reported either as the mean age of development with some measure of confidence required or as a likelihood of the stage of 
tooth development being reached at a certain age. The method of age calculation is by comparing to an atlas of tooth development ${ }^{22}$ (Figure 4) or by using a regression formula.

In adults the large variability in the dental traits currently routinely used for age estimation means that accuracy is low. One technique that has a very high level of accuracy but that depends on expensive equipment and good laboratory support is aspartic acid racemisation. During the course of ageing, L-forms of amino acids are transformed by racemisation to the d-forms at a highly constant rate. The extent of racemisation may be used to estimate the age of various tissues. Aspartic acid racemisation analysis for the purpose of age estimation has been performed on both tooth enamel and crown dentin with analysis of crown dentin shown to yield more accurate age estimation than dental enamel ${ }^{23}$.

\section{Bite mark identification and analysis}

Bite mark identification and analysis is the most contentious aspect of forensic dentistry due to the subjectivity of the process and the consequences of an incorrect report. Human or animal bite marks may be found on foodstuffs or upon the victim of an assault or manslaughter. There are two main questions relating to bite marks: does each dentition produce a unique mark and how accurately does the substrate (often human skin) reproduce the dentition that caused the bite mark. With modern computer 3-D analysis and an accuracy threshold of $0.1 \mathrm{~mm}$ it is possible to identify each arch amongst a group of arches. However, this level of accuracy is unlikely to be able to be achieved in bite mark analysis. To date it has not been possible to accurately model how human skin reacts when it is bitten. Too many variables need to be defined including; elasticity of the tissue, orientation of the bite mark, 
whether it overlies muscle, bone or soft tissue, the bite force, age of the victim, any medical conditions or medications and rate of healing.

There are two stages with this work: bite mark identification and subsequently bite mark analysis. "Is this a bite mark?" is the first question that needs to be answered (Figure 5). If it is a bite mark a decision has to be made as to whether it is caused by a human (Figure 6) or an animal (Figure 7) and if the bite mark is sufficiently clear to allow a comparison to be undertaken with the dental characteristics of the suspect's dentition ${ }^{7}$.

The use of Polymerase Chain Reaction (PCR), an enzymatic amplification of a specific DNA sequence, is routinely used to detect "salivary" DNA deposited on bite marks" ${ }^{24}$. DNA analysis has also had a significant effect on the admission of bite mark analysis in court. A number of rulings, which relied on bite mark evidence for conviction, have been overturned in the United States of America. Recent American reports are highly critical of the lack of scientific evidence supporting bite mark analysis ${ }^{25,26}$.

\section{Forensic dentistry in the future}

Identification by dental means is a proven and validated technique that is well established. The reduction in caries along with the increase in orthodontic treatment that produces an even smile will make dental identification more challenging. The use of 3-D imaging, facial and dental scanning and the increased use of "selfie" images are avenues that have the potential to address these issues. 
Much of the research currently taking place in forensic dentistry is focused on improving the accuracy of age estimation especially around the child/adult threshold ages (16 to 21 years). Many studies are developing reference groups for different ethnicities throughout the world. This is improving the accuracy but the holy grail of a highly accurate and reliable method has not been identified and it is likely that such a method will come from a chemical or DNA source rather than dental sources.

Bite mark analysis needs to be developed in a more objective manner if it is to continue to be admissible in court. Continued development of 3-D imaging, ultra-violet and infra-red photographic techniques look promising. Digital processing of images is taking away some of the subjectivity and computer algorithms have promise in bite mark identification and comparison. However, the ability to explain the evidence to a jury in an understandable manner continues to be challenging. Witness training in public engagement and clear speaking already helps and the use of computer imaging including 3-D rendering is being developed. The genotype composition of oral bacteria can also be used for identification and may help in bite mark cases by proving it was saliva that left the suspects DNA. The human oral cavity has a large combination of bacterial flora that can be unique to individuals and transferred during the act of biting. ${ }^{8}$ Emerging technologies enhance the unbiased efficacy and speed of analysis and might also reduce cost.

There is a discussion about the introduction of this subject into the Bachelor of Dental Surgery (BDS) curriculum in a number of countries as dental practitioners should have a proper knowledge of forensics for handling the medico-legal cases in their future practice ${ }^{27}$. 
However, this is complicated in an international level because of the lack of quality control in education. Moreover, forensic dentistry is a particularly complex topic for dentists many of whom are not prepared to deal with death so closely. Therefore, it would seem sensible to train people at a postgraduate level where it is more likely to be able to achieve some form of agreement of what topics and protocols need to be taught. This will need a review of existing guidelines which need to be based on experience and best practice until research provides evidence on the efficacy of different procedure enabling professionals to reach a wellfounded decision in a rigorous and structured way ${ }^{28}$. Forensic dentists are not obliged to deliver a defined result but are obliged to be conscientious, prudent and unbiased ${ }^{28}$.

\section{Conclusion}

Forensic dentistry can be intellectually rewarding but the decisions made can have significant social consequences especially when dealing with evidence in criminal cases such as child abuse or sexual assaults or when identifying multiple victims. The unpredictable timing of the work makes it difficult to fit into a normal clinical routine meaning that it is often done at night, lunchtimes or at the expense of regular patients. Very few dentists have a full time forensic role and research opportunities are limited due to the funding of this work on a case by case basis by the authorities. In addition, the nature of the work makes it difficult to design robust scientific studies using real cases which do not affect the process of justice and maintain the necessary respect for the subjects.

Whilst forensic dentistry continues to be strengthened by technological advances, improved materials and modern methodologies it is interesting to see note the similarity in day to day 
work between now and 50 years ago. An analysis of the successes and errors of the past are helping to upgrade the rigour of forensic dentistry. With lively debate amongst forensic dentists about methodologies, training and validation along with the increasing research evidence forensic dentistry is addressing the challenges of the $21^{\text {st }}$ century.

\section{References}

1. Balachander N, Babu N, Jimson S, Priyadharsini C, Masthan K. Evolution of forensic odontology: An overview. Journal of Pharmacy \& Bioallied Sciences. 2015;7(Suppl 1):S176S80.

2. Bruce-Chwatt RM. A brief history of Forensic odontology since 1775. Journal of Forensic and Legal Medicine. 2010;17(3):127-30.

3. 1819 Cotton Mills and Factories Act (59 Geo. III c66)

4. 1844 Factory Act of 1844 (7 \& 8 Vict c15)

5. Taylor D. The law and the dentist. Br Dent J. 1963; 114: 389-392.

6. Pretty IA, Sweet D. forensic dentistry: A look at forensic dentistry - Part 1: The role of teeth in the determination of human identity. Br Dent J. 2001;190(7):359-66.

7. Avon SL. Forensic odontology: The roles and responsibilities of the dentist. J Can Dent Assoc. 2004(70):453-8.

8. Waleed P, Baba F, Alsulami S, Tarakji B. Importance of Dental Records in Forensic Dental Identification. Acta Informatica Medica. 2015;23(1):49-52.

9. Shanbhag VK. Significance of Dental Records in Personal Identification in Forensic

Sciences. Journal of Forensic Science and Medicine 2016 January 1, 2016;2(1):39-43.

10. Chiam S. A note on digital dental radiography in forensic odontology. Journal of Forensic Dental Sciences 2014 Sep-Dec;6(3):197-201.

11. Sholl SA, Moody GH. Evaluation of dental radiographic identification: an experimental study Forensic Sci Int (2001); 115: 165-169

12. Wenzel A, Richards A, Heidmann J. Matching simulated antemortem and post-mortem dental radiographs from human skulls by dental students and experts: testing skills for pattern recognition. J Forensic Odontostomatol 2010 Dec 1; 28(1):5-12.

13. Almeida MA, Phillips C, Kula K and Tulloch C. Stability of the palatal rugae as landmarks for analysis of dental casts. The Angle Orthodontist. 1995; 65(1): 43-48.

14. De Angelis D, Cattaneo C and Grandi M. Dental superimposition: a pilot study for standardising the method. Int J Legal Med 2007;121:501-506.

15. Silva RF, Pereira SD, Prado FB, Daruge Junior E and Daruge E. Forensic odontology identification using smile photograph analysis - case reports. J Forensic Odontostomatol 2008

16. Moody GH, Busuttil A, and Hill PG, A common origin for dental porcelain derived from an accused's hand and the decreased victim of an assault. Int J Legal Med 1992; 105(3): 17983

17. Gupta B, Datta S, Datta P. Application of Molecular Biology in Forensic Dentistry. Indian Journal of Forensic Odontology. 2012;5(3):105. 
18. Krishan K, Kanchan T, Garg AK. Dental Evidence in Forensic Identification - An Overview, Methodology and Present Status. The Open Dentistry Journal. 2015;9:250-6.

19. Singh N, Grover N, Puri N, Singh S, Arora S. Age estimation from physiological changes of teeth: A reliable age marker? Journal of Forensic Dental Sciences. 2014 MayAug;6(2):113-21.

20. Cole TJ. The evidential value of developmental age imaging for assessing age of majority. Annals of human biology. 2015 Jul 2:1-10.

21. Elamin F, Liversidge HM. Malnutrition Has No Effect on the Timing of Human Tooth Formation. PLoS ONE. 2013;8(8):e72274.

22. AlQahtani SJ, Liversidge HM and Hector MP Atlas of tooth development and eruption. 2010. American Journal of Physical Anthropology;142(3):481-90

23. Alkass K, Buchholz BA, Ohtani S, Yamamoto T, Druid H, Spalding KL. Age Estimation in Forensic Sciences: Application of combined aspartic acid racemization and radiocarbon analysis. 2010. MCP;9(5):1022-1030.

24. Silva R, Musse J, Melani RFH, Oliveira RN. Human bite mark identification and DNA technology in forensic dentistry. Braz J Oral Sci. 2006(5):1193-7.

25. National Academy of Science. Strengthening forensic science in the United States: a path forward. Washington DC: The national academies press 2009. https://www.nap.edu/read/12589

26. President's Council of Advisors on Science and Technology (PCAST) Forensic Science in Criminal Courts: Ensuring Scientific Validity of Feature-Comparison Methods. 2016 https://www.whitehouse.gov/sites/default/files/microsites/ostp/PCAST/pcast_forensic_scienc e_report_final.pdf

27. Singh NN, Gowhar O, Ain TS, Sultan S. Exploring Trends in Forensic Odontology. JCDR. 2014; 8(12): ZC28-ZC30.

28. Vermylen Y. Guidelines in forensic odontology: legal aspects. Forensic science international. 2006;159, Supplement:S6-S8. 
Figure legends for forensic dentistry paper for RCPSG update

Figure 1a: ante mortem radiograph of post crown

Figure $1 \mathrm{~b}$ : post mortem radiograph of tooth showing the same shape of metal structure ad root filling shape.

Figure 2a: Ante mortem cast of suspected victim

Figure $2 \mathrm{~b}$ : mandible of victim. When compared the shape, size of teeth and the space between LR3 and LR4 matched the cast so identity was established

Figure 3a: A training exercise for DVI where a rail crash was simulated.

Figure 3b: A temporary mortuary set up for the DVI scenario with different stations through which victims pass: finger print, personal belongings, medical examination, imaging and dental examination

Figure 4: an example of an age image from the London Atlas of tooth development and eruption. A radiograph is examined and the closest image is considered to be the most likely age (courtesy of Professor Liversidge, Professor Hector and Dr AlQahtani).

Figure 5: a suspected bite mark deemed not to be one

Figure 6: a human bite mark

Figure 7: a dog bite 
Figure 1 (a)

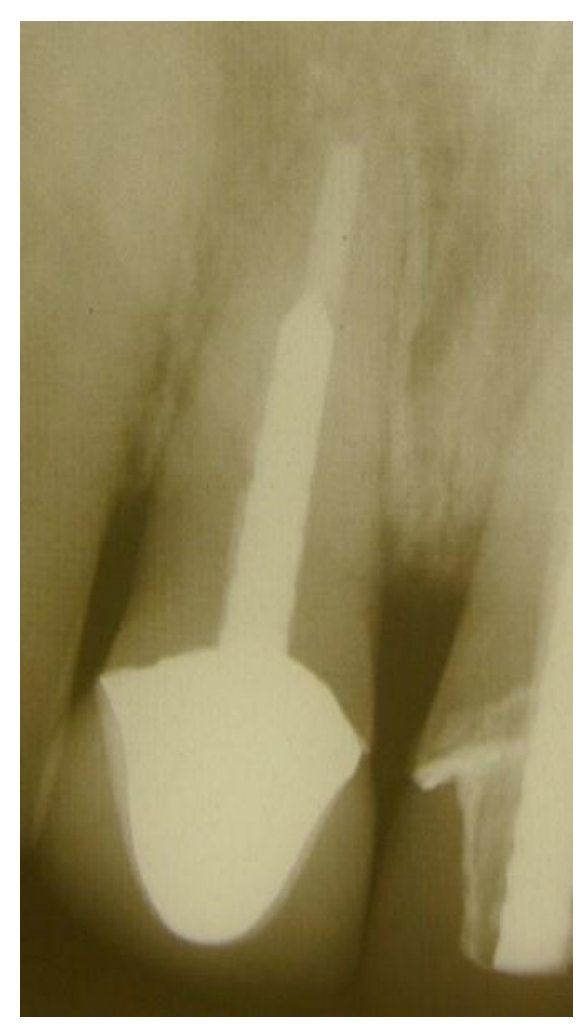

(b)

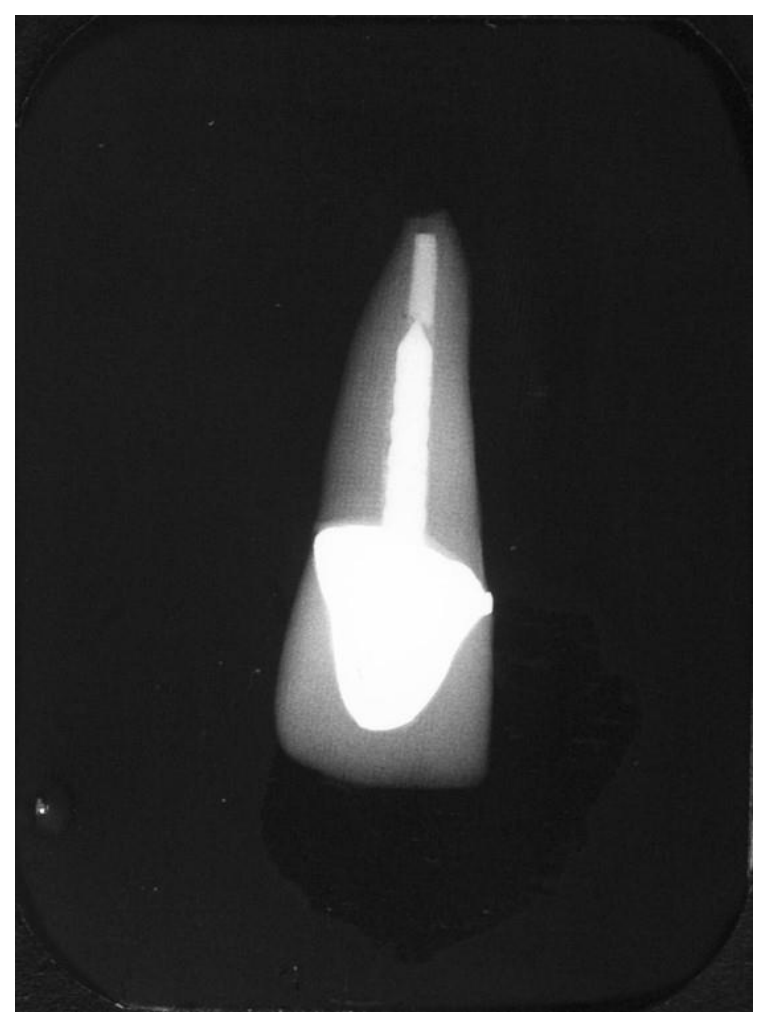


Figure 2 (a)

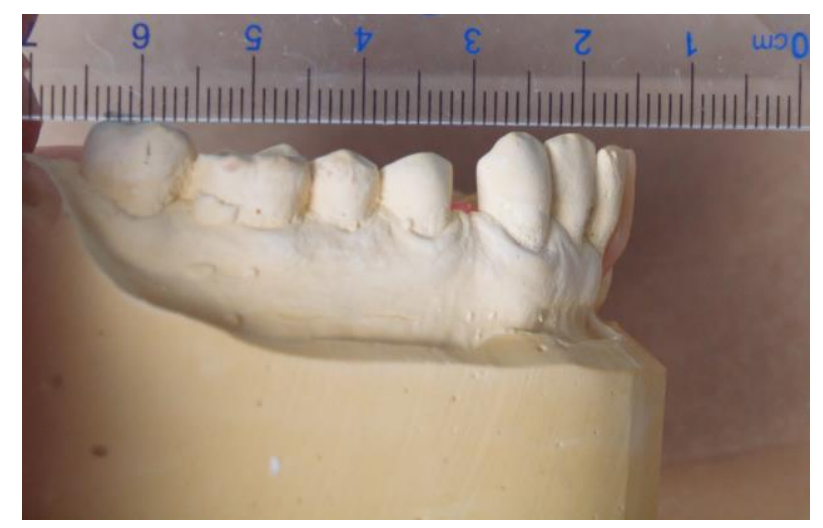

(b)

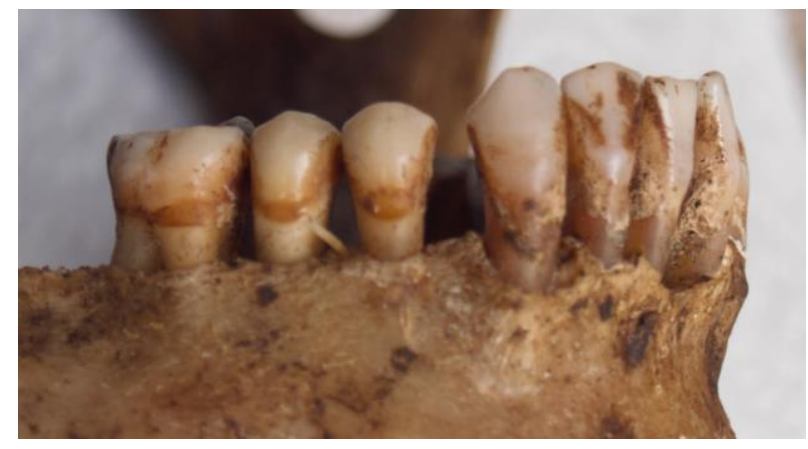


Figure 3 (a)

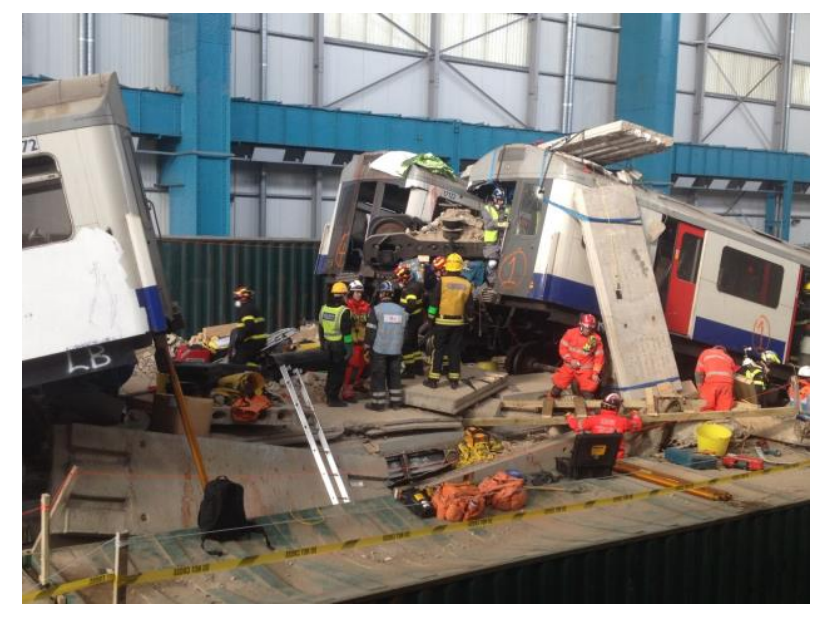

(b)

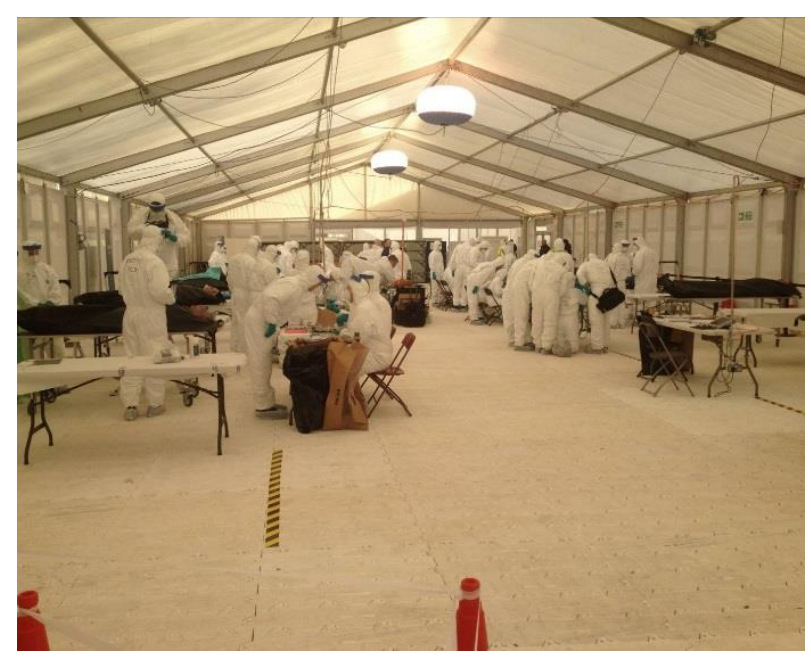




\section{$8.5 \mathrm{yr}$}

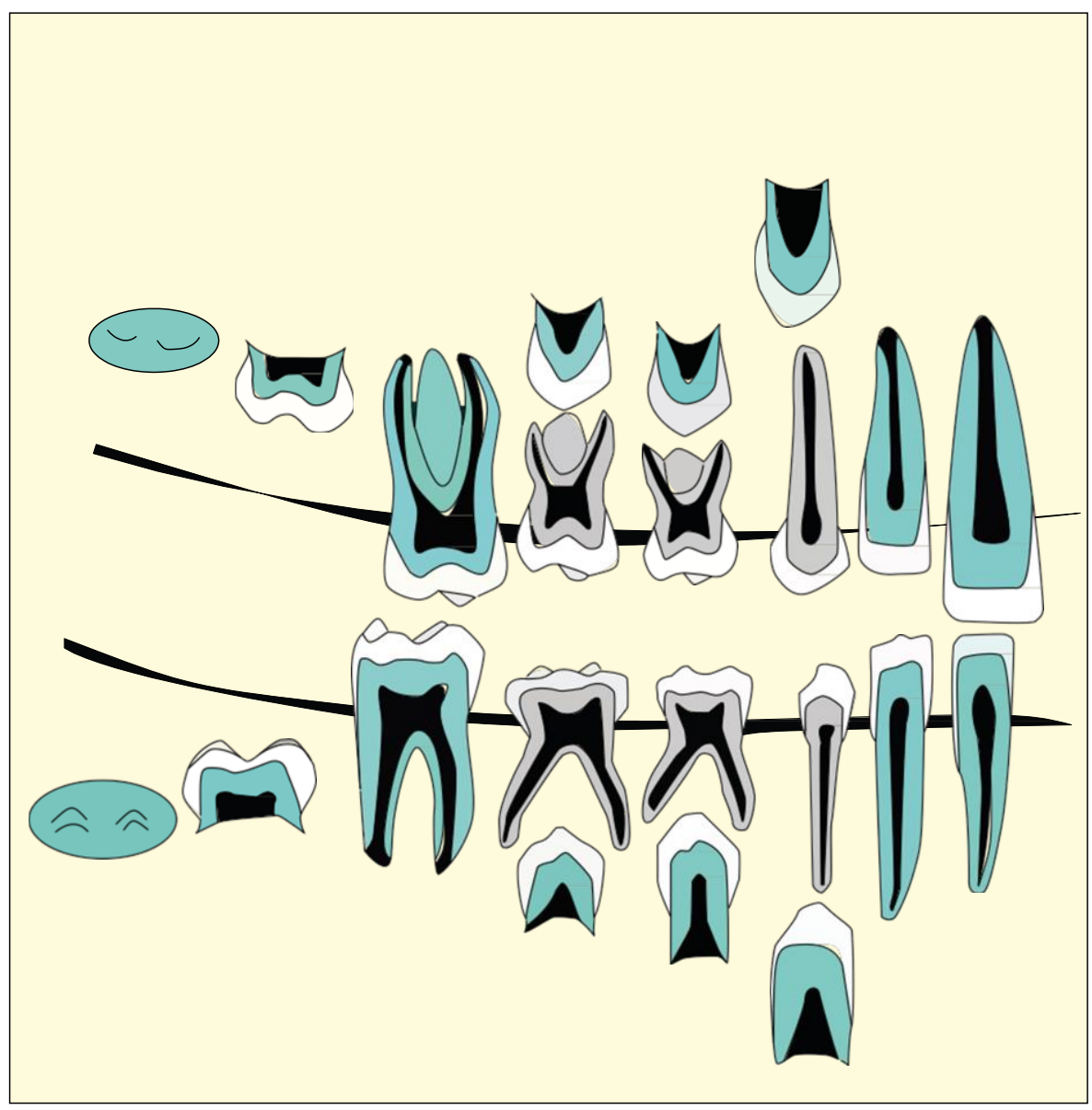

Figure 4. An example of an age image from the London Atlas of tooth development and eruption. A radiograph is examined and the closest image is considered to be the most likely age (courtesy of Professor Liversidge, Professor Hector and Dr AIQahtani). 
Figure 5

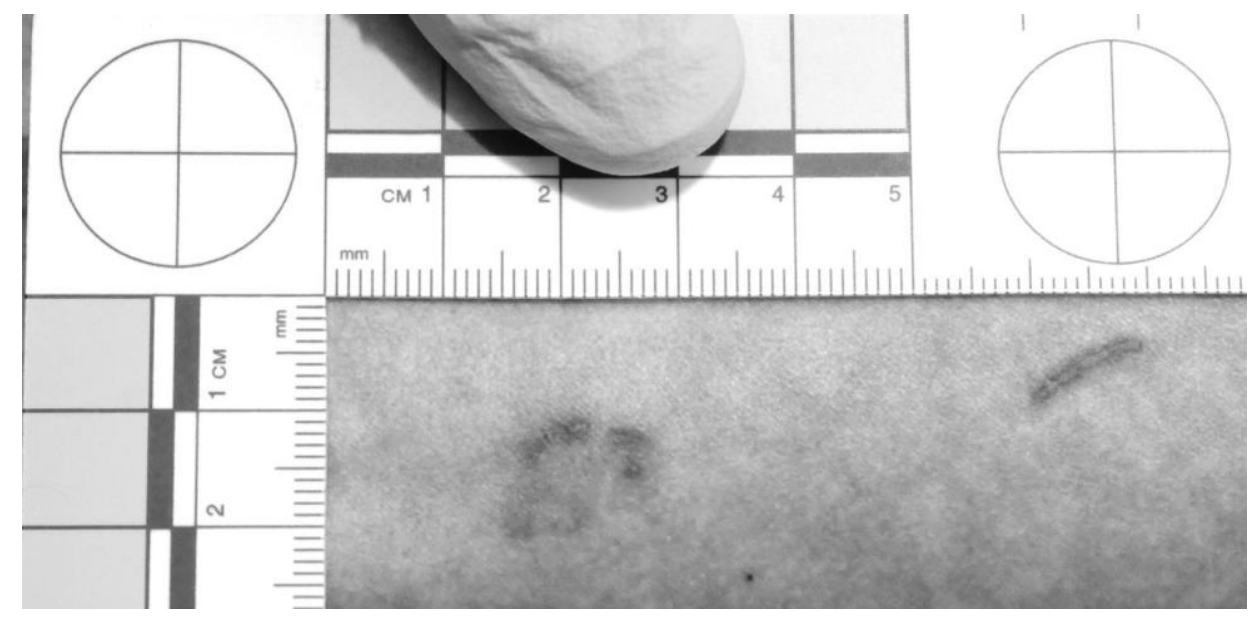


Figure 6

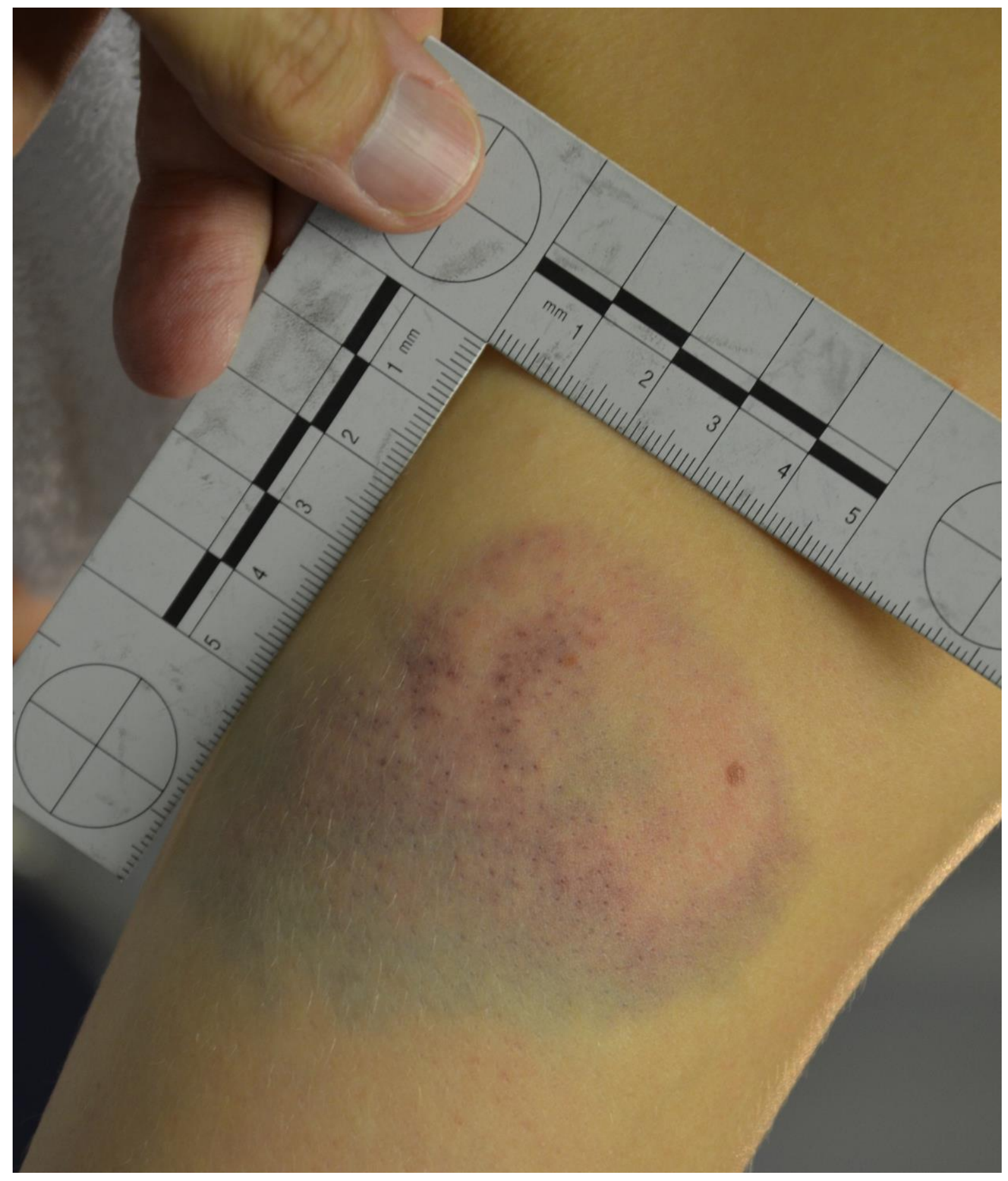


Figure 7

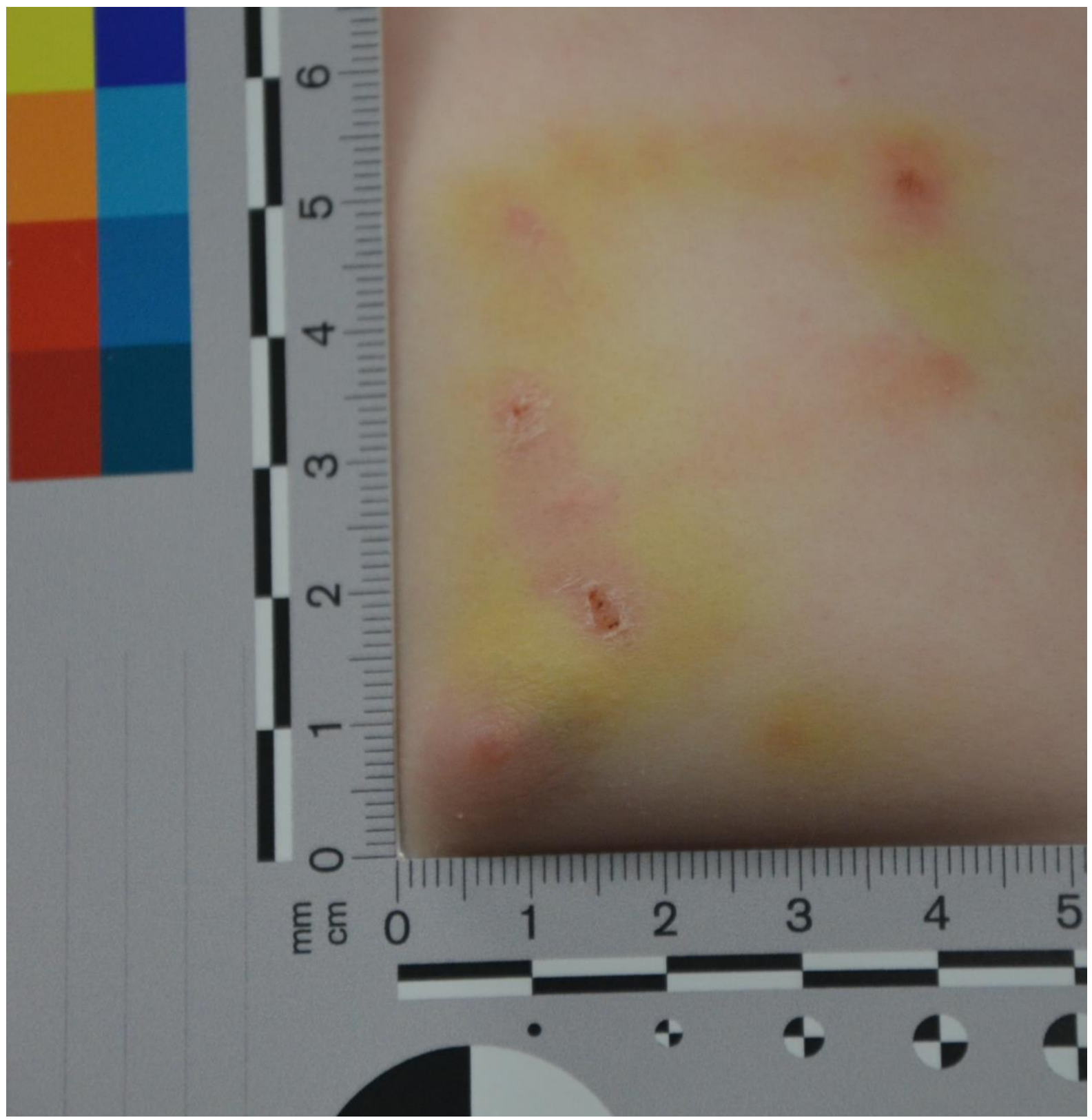

